\title{
Uso do E-book Como Meio de Compartilhamento Formal e Disseminação do Conhecimento Explicito em Organizações
}

Use of e-book as formal resource of sharing and dissemination of explicit knowledge in organizations

Adriane lanzen Machado ${ }^{9}$

Fabiana Paula Hoffmann

Egon Walter Wildauer

\section{Resumo}

Há uma grande gama de conhecimento fragmentado dentro das organizações, principalmente pelo fato dos conhecimentos estarem dentro da particularidade de cada indivíduo, que carrega seus saberes conforme suas experiências, cultura, vivências. Fato este que remete ao que se pode chamar de conhecimento tácito, que é algo individual e importante para a construção do conhecimento explícito. O uso de ferramentas tecnológicas é de suma importância como meio de disseminação deste conhecimento, neste sentido este artigo tem como objeto de estudo o uso do livro eletrônico (e-book) como ferramenta estratégica para a materialização do conhecimento e, consequentemente, para sua disseminação. Os aspectos fundamentais e conceituais referentes ao e-book, gestão do conhecimento, materialização do conhecimento, ativista do conhecimento e o livro eletrônico fazem parte do cenário do objeto de estudo e é com base nestes conceitos que surge uma proposta de uso do livro eletrônico como ferramenta tecnológica de disseminação do conhecimento. O método de pesquisa adotado foi a pesquisa bibliográfica com análise da literatura sobre os livros eletrônicos, em seu novo surgimento, no século XXI, resultando no levantamento dos conceitos potenciais para o compartilhamento dos conhecimentos das organizações. Foi realizada uma análise qualitativa de teorias que sustentam a criação de um meio para a disseminação formal do conhecimento por meio dos e-books. Constatou-se que materializar o conhecimento utilizando-se do e-book pode ser uma ferramenta estratégica e tecnológica para agregar valor às organizações, uma vez que o usuário pode ter acesso em tempo real ao conhecimento utilizando-se tanto de

9 Adriane lanzen Machado: Mestranda do Programa de Mestrado em Gestão e Tecnologia da Informação. Universidade Federal do Paraná - UFPR. Curitiba, PR Brasil. E-mail: adriane@iagil.com.br

Fabiana Paula Hoffmann: Mestranda do Programa de Mestrado em Gestão e Tecnologia da Informação. Universidade Federal do Paraná - UFPR. Curitiba, PR Brasil. E-mail: fsilvadm@yahoo.com.br

Egon Walter Wildauer: Doutor em Ciências Florestais pela Universidade Federal do Paraná (UFPR), Brasil. Mestre em Engenharia de Produção pela Universidade Federal de Santa Catarina (UFSC), Brasil. Professor do Programa de Mestrado em Ciência, Gestão e Tecnologia da Informação (UFPR). Orientador. E-mail: egon@ufpr.br. 
computadores como de aparelhos celulares, o que gera uma competitividade e um poder de conhecimento vantajoso para as organizações.

Palavras-Chave: E-book, conhecimento tácito e explícito, gestão do conhecimento, ativista do conhecimento, materialização do conhecimento.

\section{Abstract}

There are a wide range of fragmented knowledge within organizations, mainly because knowledge are within the particularity of each person who carries their knowledge according their experiences, culture and way of life. This fact leads to what might be called tacit knowledge, which is something personal and important to construct the explicit knowledge. The use of technological tools has a great importance as a way of disseminating explicit knowledge and, in this sense, this paper has the objective study the use of electronic book (e-book) as a strategic tool in order to materialization the knowledge and, consequently, its spread. The fundamental and conceptual aspects related to e-book, knowledge management, knowledge's materialization, knowledge's activist and the electronic book make part of the scenery of the object of study and part of these concepts, emerges a proposal to use the electronic book as a technological tool for knowledge dissemination. The research method used was a literature review with analysis of them on e-books in his new appearance, in the twenty-first century, resulting in a survey of potential concepts for the knowledge sharing in organizations. Quantitative analysis was performed over the theories that support the creation means for formal dissemination of knowledge through the e-books. As a result, these paper found that materialize the knowledge using e-book can be a strategic and technological tool to add value in organizations, since the user can have real time access to knowledge using both computers and cell phones, which generates competitivity and a power knowledge advantage for organizations.

Key-words: E-book, explicit and tacit knowledge. knowledge management, knowledge's activist, knowledge's materialization.

\section{INTRODUÇÃO}

A tecnologia, e seu constante aprimoramento, é responsável por grande parte das revoluções em qualquer campo ou área de conhecimento. Desde que a internet foi disponibilizada para acesso público e sua popularização permitiu a intensa troca de informações entre pessoas de diversas partes do planeta, ocorreu a multiplicação de informações e o grande aumento no desenvolvimento do conhecimento. Nesse ínterim, surgiu a Sociedade da Informação e mais tarde a Sociedade do Conhecimento. Os desafios da colaboração, disseminação, transmissão estão presentes em ambas Sociedades coexistentes no mundo.

Organização, armazenamento, disseminação são termos muito conhecidos pela Sociedade da Informação. Sociedade esta que, junto com 
o avanço das tecnologias da informação e comunicação, trouxe uma revolução no campo da comunicação, da transmissão de dados e informações. Com essa revolução algo a mais foi evidenciado: o crescimento do conhecimento.

No momento vive-se uma intensa '(r)evolução' em um produto que é muito tradicional para o ser humano e que está totalmente relacionado com a transmissão de informações e com o conhecimento: o livro. Esta (r)evolução está pautada, principalmente, na alteração do suporte do livro que passa do impresso ao digital, convencionalmente tratado de livro eletrônico, ou e-book.

O e-book não é uma tecnologia do século $\mathrm{XXI}$; sua existência é mais antiga, porém neste século alguns conceitos em relação a essa tecnologia foram modificados, concomitante ao ressurgimento dos aparelhos leitores, ou seja, os e-readers. Estes aparelhos também não são novidades no mundo tecnológico, embora a sua força de mudança e inovação sejam os novos leitores digitais, acompanhados das pranchetas eletrônicas (ou tablets), que ressurgem com foco corporativo, ao invés de meros equipamentos para leitura e/ou entretenimento de seus usuários.

A crescente preocupação empresarial com seu ativo financeiro interno tem foco para o ser humano, seu colaborador com suas competências e habilidades em gerar e transmitir conhecimentos.

Apesar de o conhecimento ser algo muito comentado e discutido dentro das organizações, há ainda muita dificuldade nas empresas em realmente se utilizar adequadamente os conhecimentos gerados internamente. Na prática, gerir o conhecimento é algo ainda nebuloso para muitas instituições e uma das possíveis causas para isso, é a negligência das instituições no momento da externalização dos conhecimentos. Quem afirma isto são os autores Takeuchi e Nonaka (2008), pois, para eles, este processo tem sido amplamente negligenciado na literatura organizacional.

As ferramentas colaborativas e de socialização, públicas na web, também interagem-se neste contexto de geração e compartilhamento de conhecimentos, nas quais as empresas devem estar inseridas. Torquato (2008), no prefácio do livro Sociedade da Informação, comenta sobre o surgimento da web 2.0 e sobre o aumento da disponibilização e do consumo de recursos de áudio e vídeo. De forma generalizada, comenta ainda que essa situação compreende também "outras características inovadoras, como aquelas oferecidas pelas redes e comunidades sociais e empresariais, pelos sistemas colaborativos Wiki e por meio da crescente geração e difusão de conteúdo pelos próprios usuários" (TORQUATO, 2008, prefácio). É nesse contexto que se insere a nova era dos livros digitais. Desta forma questiona-se então: como aproveitar essa ferramenta tão valiosa nas empresas, para que auxilie na produtividade e competitividade empresarial?

Com base nesta questão pretende-se entender como os livros eletrônicos podem se apresentar como uma ferramenta útil na disseminação do conhecimento. Dessa forma este artigo tem como objetivo apresentar uma proposta de uso de e-books e seus aparelhos leitores (sejam ereaders, sejam tablets, sejam aparelhos celulares) como uma estratégia 
para a gestão e o compartilhamento de conhecimentos dentro de uma organização.

\subsection{Estrutura}

Este artigo está estruturado em seis tópicos de forma que no primeiro é apresentado um breve histórico sobre os e-books; no segundo apresenta-se uma atualização devida à evolução do conceito; para então adentrar, no terceiro tópico, nos temas gestão do conhecimento e disseminação formal do conhecimento; a materialização do conhecimento é foco do quarto tópico e o uso de e-books como disseminação formal do conhecimento externalizado é proposto no sexto tópico. Em fim apresentam-se as considerações finais com base nos autores que serviram como apoio teórico para a construção da proposta.

\subsection{Procedimentos Metodológico}

Os procedimentos metodológicos adotados para esta pesquisa foram: levantamento bibliográfico e análise de literatura com os temas abordados de acordo com 0 quadro 1 , seguido de análise qualitativa dos conhecimentos potenciais compartilhados para viabilizar uma proposta de disseminação de conhecimentos dentro das organizações por meio de uma ferramenta tecnológica, neste caso os livros eletrônicos. 


\begin{tabular}{|c|c|c|}
\hline $\begin{array}{c}\text { REVISÃO } \\
\text { BIBLIOGRÁFICA }\end{array}$ & $\begin{array}{c}\text { TÓPICO } \\
\text { CORRESPONDENTE }\end{array}$ & $\begin{array}{l}\text { CONTRIBUIÇÃO PARA AS } \\
\text { ORGANIZAÇÕES }\end{array}$ \\
\hline $\begin{array}{lr}\text { BARRETO, } & 2011 ; \\
\text { BENÍCIO, } & 2003 ; \\
\text { DZIEKANIAK, } & 2010 ; \\
\text { GARCIA, } & 2010 ; \\
\text { GUTENBERG, } & 2008 ; \\
\text { SILVA \& BUFREM, } \\
\text { 2001; YANO, 2010 }\end{array}$ & $\begin{array}{l}\text { Histórico sobre os } e^{-} \\
\text {books }\end{array}$ & $\begin{array}{l}\text { Propicia o conhecimento sobre o } \\
\text { cenário de e-books. }\end{array}$ \\
\hline $\begin{array}{l}\text { DZIEKANIAK, } 2010 ; \\
\text { IDPF, } 2010\end{array}$ & $\begin{array}{l}\text { Atualização de conceitos } \\
\text { em relação aos e-books }\end{array}$ & $\begin{array}{l}\text { Definição e distinção do conceito de } \\
\text { E-books e aparelhos leitores. }\end{array}$ \\
\hline 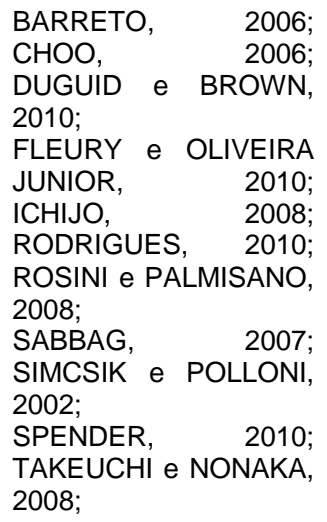 & $\begin{array}{ll}\text { A gestão } & \text { do } \\
\text { conhecimento e } & \text { a } \\
\text { disseminação formal do } \\
\text { conhecimento }\end{array}$ & $\begin{array}{l}\text { Importância da disseminação formal } \\
\text { do conhecimento como estratégia } \\
\text { competitiva para as organizações, } \\
\text { utilizando-se da tecnologia e do } \\
\text { ativista para a elaboração, para o } \\
\text { compartilhamento e para a troca } \\
\text { formal de conhecimentos. }\end{array}$ \\
\hline $\begin{array}{lr}\text { GROTTO, } & \text { 2003; } \\
\text { MUÑOZ-SECA } & \text { e } \\
\text { RIVEROLA, } 2004 & \end{array}$ & $\begin{array}{l}\text { Materialização } \\
\text { conhecimento }\end{array}$ & $\begin{array}{l}\text { Propõe uma estruturação formal e } \\
\text { concreta do conhecimento. }\end{array}$ \\
\hline $\begin{array}{l}\text { NONAKA e TAKEUCHI, } \\
\text { 1997; } \\
\text { SANTIAGO JUNIOR, } \\
\text { 2004; } \\
\text { REZENDE, } \\
\text { TEIXEIRA FILHO, } 2002 \text {; }\end{array}$ & $\begin{array}{l}\text { O livro eletrônico como } \\
\text { estratégia para a gestão } \\
\text { do conhecimento }\end{array}$ & $\begin{array}{l}\text { Contribui para integrar e sistematizar } \\
\text { formalmente os conhecimentos } \\
\text { fragmentados, inibindo os problemas } \\
\text { com falhas na transferência desses e } \\
\text { adequando em tempo real, não } \\
\text { limitado a um local físico (estático), as } \\
\text { alterações que ocorrem dentro das } \\
\text { organizações, tornando-as dinâmicas } \\
\text { e competitivas. } \\
\text { Por meio da socialização, } \\
\text { externalização, internalização e a } \\
\text { combinação é possível a migração do } \\
\text { conhecimento tácito em conhecimento } \\
\text { explícito contribuindo para a } \\
\text { formalização e registro dos } \\
\text { conhecimentos gerados pelas } \\
\text { organizações. }\end{array}$ \\
\hline
\end{tabular}




\title{
2 BREVE HISTÓRICO SOBRE OS E-BOOKS
}

O conceito de livro eletrônico não é recente, conforme Garcia (2010, p. 1) "antes mesmo de e-books, e-readers ou dos blogs, já era possível distribuir uma obra pela internet. Não por acaso, a rede possibilitou, em poucos anos, um boom (sic) na produção de conteúdo".

Em 1945, Vannevar Bush (diretor do Escritório de Pesquisas e Desenvolvimento dos EUA) idealizou o primeiro aparelho leitor de livros que ele chamou de Memex. Em 1968, Allan Kay (um cientista norte-americano da Xerox Corporation) previu o aparecimento, por volta dos anos 90, de um livro dinâmico que seria uma espécie de computador portátil, pequeno de duas telas, com textos, ilustrações, colorido e legibilidade perfeita. Inclusive esse cientista imaginava a possibilidade de imitar o virar de páginas apertando botões ou mesmo tocando na tela. (SILVA; BUFREM, 2001).

Em 1971 Michael Hart fundou, nos EUA, o Projeto Gutenberg (GUTENBERG, 2008), uma iniciativa que criou os livros eletrônicos, oferecendo, atualmente, mais de 36.000 livros livres para download e leitura em diversos tipos de aparelhos.

Em 1992, a Apple:

\begin{abstract}
inaugurou o mercado de computadores de bolso com o Newton, um fracasso estrondoso de vendas. Sony, Philips e Sharp foram igualmente derrotadas na missão de emplacar um portátil. Quem conseguiu tirar os handhelps do anonimato e transformá-los em ícones dos anos 90 foi a até então desconhecida Palm Computing. (...) Entre seus atrativos, uma tela monocromática que reconhecia escrita com canetinha (stylus), a troca de dados por infravermelho e 1MB de memória para guardar contatos. Para baixar e-mails era preciso comprar um modem e acoplar. (BARRETO, 2011, p. 134)
\end{abstract}

Este fracasso inicial não desanimou os investidores deste tipo de aparelho, surgindo entre a década de 90 e o ano 2000 diversos tipos de aparelhos leitores, cada um com suas funcionalidades e particularidades, procurando ganhar o mercado (BENÍCIO, 2003).

Após o ano 2000 houve uma espécie de revolução no mercado de $e$ readers, visto que a partir do lançamento do Kindle, aparelho leitor de propriedade da Amazon, houve um grande aumento no desenvolvimento de novos aparelhos leitores (YANO, 2010).

Devido ao crescente uso e interesse dos e-books, em meados do ano 2000 , houve a necessidade de uma atualização do conceito de e-book, pois tanto $o$ arquivo do livro quanto os aparelhos leitores eram chamados de $e$ books. A seguir apresenta-se essa atualização de conceitos, a qual diferencia os arquivos de livros eletrônicos de aparelhos leitores. 


\section{ATUALIZAÇÃO DE CONCEITOS EM RELAÇÃO AOS E- BOOKS}

Após o surgimento dos primeiros e-books houve uma mudança radical no seu conceito, o qual, inicialmente, se confundia com software, hardware e conteúdo. Em vários artigos publicados sobre o livro eletrônico, verifica-se o uso do termo e-book para designar tanto o arquivo do livro quanto os aparelhos leitores (BENÍCIO, 2003; BENÍCIO; SILVA, 2005; BUFREM; SORRIBAS, 2009; DZIEKANIAK, 2010; SILVA; BUFREM, 2001, entre outros), uma vez que a terminologia estava em processo de desenvolvimento e necessitava de um maior "tratamento por parte das áreas envolvidas com o estudo dos suportes informacionais" (DZIEKANIAK, 2010, p. 2).

Esse conceito passou a se firmar a partir do desenvolvimento dos ereaders, seguidos dos tablets, assim como também o formato dos livros (arquivo) também se e modificou. Antes haviam os Portable Document Format (PDF), Text (TXT), HyperText Markup Language (HTML), logo, surgiu o Extensible Markup Language (XML) com o conceito de organização do conteúdo, com apoio de linguagens de formatação como o Extensible Stylesheet Language (XSL) e o Cascading Style Sheets (CSS), e então chegou-se ao ePub (eletronic publishing), um formato que agrega as funções do HTML, XML e CSS e que é um padrão aberto, desenvolvido em 2007, pelo IDPF (International Digital Publishing Forum). Este formato está na sua versão 3, lançada em outubro de 2011 e abrange funcionalidades como multimídia e a linguagem JavaScript (IDPF, 2010).

Até o surgimento do ePub os fabricantes de e-readers procuravam criar um formato compatível com o seu próprio e-reader, os chamados formatos proprietários, de forma a garantir que o leitor que o adquirisse, tivesse que comprar os livros somente de sua própria plataforma. O ePub transformou-se em um unificador de tecnologias, tornando-se o formato padrão usado pela maioria dos aparelhos desenvolvidos para este fim.

Definido o conceito de e-book e sua utilidade como documento virtual e atualizável em qualquer circunstâncias, este tipo de tecnologia proporciona um meio de disseminar formalmente os conhecimentos dentro das organizações, o que se torna uma ferramenta estratégica para a gestão do conhecimento.

\section{A GESTÃO DO CONHECIMENTO E A DISSEMINAÇÃO FORMAL DO CONHECIMENTO}

Para se chegar à Gestão do Conhecimento, houve uma linha do tempo a ser percorrida pelas organizações, o que é bem explicitado por Barreto (2006) que coloca a gestão do conhecimento dentro de uma ciência, a ciência da informação. O autor a considera como: "uma instituição mediadora da relação informação-conhecimento" (BARRETO, 2006, p. 11) e apresenta tempos distintos na história desta ciência: "tempo de gerência da 
informação, que vai de 1945 a 1980" no qual ele comenta o início da necessidade de organizar, indexar e recuperar informações"; "tempo de relação entre informação e o conhecimento, no período de 1980 a 1995", no qual o autor identifica o início da relação direta entre informações e conhecimento; e o "tempo do conhecimento interativo, de 1995 até 2006", data de publicação da obra do autor, que comenta da interatividade após o advento da internet e de sua disponibilização para o acesso público.

Pode-se acrescentar aos tempos identificados pelo autor, o tempo do conhecimento colaborativo, iniciado desde que surgiram os blogs e ferramentas de construção colaborativa na web (chamadas wiki). Surgiu nesse panorama, não só interatividade na web, mas a construção mútua de informações e conhecimentos, como ferramentas essenciais em diversas áreas.

Redes de relacionamento social fazem parte desse avanço, nas quais grupos de opiniões e crenças adjacentes unem-se em busca de conhecimentos e compartilhamento de informações sobre seus assuntos de interesse. Nesse contexto inserem-se as comunidades de práticas organizacionais, as quais não estão apenas dentro das organizações, mas disponíveis na web a fim de colher contribuições externas. Duguid e Brown (2010) abordam a existência de comunidades de práticas nas organizações como grupos que se desenvolvem espontaneamente e enfatizam que essas comunidades trocam entre si e criam conhecimentos, muitas vezes por meio do improviso (inovação). No entanto, afirmam que:

\begin{abstract}
o conhecimento dividido entre as comunidades diferentes de uma organização não equivale a um todo coerente, do qual as melhores partes ou práticas possam ser selecionadas e transferidas. Ao contrário, trata-se de um grupo de conhecimento fragmentado e localmente desenvolvido, a partir do qual a organização tem que produzir outro grupo complementar e coerente. (DUGUID; BROWN, 2010, p. 71).
\end{abstract}

Duguid e Brown (2010) comentam sobre a experiência do desenvolvimento de bancos de dados, pelas comunidades de prática em determinada instituição, porém apontam como problema dessa alternativa a questão da saturação das informações em virtude de seu crescimento indiscriminado, perdendo assim seu valor e sua especificidade. A necessidade de filtro e critério no momento de preenchimento de um "repositório de conhecimento" é essencial para evitar problemas como esse de saturação.

Um ponto abordado pelos autores refere-se a intermediação do conhecimento, no qual uma sugestão seria que fosse feito por participantes que são integrantes de diversos grupos, de forma a aliar os conhecimentos entre estes grupos.

Rodrigues (2010) aborda o incentivo proporcionado pelas novas tecnologias no desenvolvimento do conhecimento organizacional:

A maior facilidade de acesso à informação, em razão da nova tecnologia e da velocidade das comunicações, criou as condições apropriadas para que o conhecimento escapasse de seus detentores tradicionais: os pequenos círculos e a elite. A multimídia, com CD-ROMS, vídeos e, acima de tudo, a Internet, 
facilitou a compactação da informação e sua distribuição indiscriminada (RODRIGUES, 2010, p. 88).

Fleury e Oliveira Junior (2010, p. 18) afirmam que "O conhecimento da empresa é fruto das interações que ocorrem no ambiente de negócios e que são desenvolvidas por meio de processos de aprendizagem. O conhecimento pode ser entendido também como informação associada à experiência, intuição e valores". Os autores consideram que os conhecimentos tácitos de um grupo de pessoas em uma organização são as competências essenciais da empresa.

\begin{abstract}
A gestão do conhecimento apresenta uma importante contribuição para a compreensão de como recursos intangíveis podem constituir a base de uma estratégia competitiva, assim como para a identificação dos ativos estratégicos que irão assegurar resultados superiores para a empresa no futuro (...). Entendemos por gestão estratégica do conhecimento a tarefa de identificar, desenvolver, disseminar e atualizar o conhecimento estrategicamente relevante para a empresa (FLEURY; OLIVEIRA JUNIOR, 2010, p. 19).
\end{abstract}

Fleury e Oliveira Junior (2010) afirmam ainda que as empresas de conhecimentos diferentes devem unir-se para suprir suas falhas potenciais de conhecimentos, de forma a manterem-se competitivas na "economia do conhecimento".

Spender (2010) comenta que as empresas geralmente têm muito conhecimento armazenado, porém de forma desestruturada e dispersa (tanto em pessoas quanto em objetos e/ou produtos da própria empresa), o que torna necessário unir o conhecimento com a tecnologia moderna para torná-lo disponível quando necessário. Em seus estudos o autor divide a Gestão do Conhecimento em duas frentes: uma que a trata como objeto (e procura abstrair o conhecimento das pessoas) e outra que a trata como processo (envolvendo os processos individuais e sociais de criatividade, inovação, motivação e comunicação), o que acaba por conduzir "mensagens diferentes para os gerentes que tentam entender o que a gestão do conhecimento realmente significa para eles" (SPENDER, 2010, p. 31).

Spender considera ainda que o valor (do conhecimento) "depende de sua habilidade [dos gerentes] de ir além da análise convencional para capturar e analisar novos fenômenos. (...) seu valor está na habilidade de dar aos gerentes maiores insights e influenciar os sistemas de atividades e a comunidade de práticas que podemos chamar de organizações" (SPENDER, 2010, p. 46).

Verifica-se, desta forma a necessidade de se considerar o ciclo da geração do conhecimento, proposto por Takeuchi e Nonaka (2008), o chamado SECI (abreviatura de Socialização, Externalização, Combinação e Internalização); Esse modelo "está no núcleo do processo de criação do conhecimento (...) e descreve como os conhecimentos tácito e explícito são amplificados em termos de qualidade e quantidade, assim como do indivíduo para o grupo e, então, para o nível organizacional." (TAKEUCHI; NONAKA, 2008, p. 23). 
Ainda é possível verificar que os autores consideram que as organizações tem negligenciado a etapa de externalização do conhecimento, que é a etapa na qual "o conhecimento tácito, que é pessoal, específico ao contexto e difícil de formalizar e comunicar aos outros, é convertido em conhecimento transmissível e articulado." (TAKEUCHI; NONAKA, 2008, p. 24)

Nonaka (2008) comenta que tornar o conhecimento tácito em explícito é o mesmo que expressar o inexpressável e sugere o uso de linguagem figurativa e de simbolismo para isso, o que tem sido frequentemente desconsiderado pelas organizações; disserta sobre alguns casos de sucesso e comenta que os responsáveis pela gestão do conhecimento devem sintetizar os conhecimentos tácitos de seus colaboradores, tanto os de linha de frente, quanto dos executivos seniores, tornando-os explícitos, de forma que sejam incorporados em novas tecnologias e produtos.

Choo (2006), corroborando com Takeuchi e Nonaka (2008), explicita de forma clara sobre o conhecimento explícito, considerando-o como aquele que

\begin{abstract}
pode ser expresso formalmente com a utilização de um sistema de símbolos, podendo portanto ser facilmente comunicado ou difundido. O conhecimento explícito pode se basear em objetos ou regras. (...) O conhecimento baseado em objetos pode ser encontrado, por exemplo, em especificações de produtos, patentes, código de software, banco de dados de computador, desenhos técnicos, protótipos, fotografias e outros. $O$ conhecimento explícito é baseado em regras quando é codificado em normas, rotinas ou procedimentos operacionaispadrão. (CHOO, 2006, p. 189).
\end{abstract}

Um papel importante para que este conhecimento seja de tal forma articulado dentro das organizações é desempenhado pelo chamado 'ativista do conhecimento', que tem como função impulsionar e fazer um elo de ligação entre os indivíduos e o conhecimento.

E que segundo o conceito proposto por Simcsik e Polloni (2002), para que o conhecimento empresarial seja coletado, armazenado e externalizado eficientemente há a necessidade da existência de um ator no processo, conhecido como o ativista do conhecimento (também chamado por alguns autores, como engenheiro do conhecimento).

Para os autores "O engenheiro do conhecimento é o profissional responsável pela estruturação e construção de um sistema inteligente. Ele extrai conhecimento de alguma fonte, interpreta e representa em tipos e estruturas convenientes" (SIMCSIK; POLLONI, 2002, p. 373). Afirmam ainda que o engenheiro do conhecimento deva possuir boa comunicação, inteligência, tática e diplomacia, empatia e paciência, versatilidade e inventividade, conhecimento do domínio, conhecimento de programação.

$\mathrm{Na}$ mesma linha de pensamento desses autores, Ichijo (2008), apresenta alguns propósitos para a existência do ativismo do conhecimento, apontando seis deles:

(1) foco e inicialização da criação do conhecimento; (2) redução do tempo e do custo necessários para a criação do conhecimento; (3) alavancagem de iniciativas de criação do conhecimento por tora a corporação; (4) melhoramento das condições daqueles engajados na criação do conhecimento, relacionando suas atividades ao quadro geral da empresa; (5) 
preparação dos participantes da criação de conhecimento para novas tarefas nas quais seu conhecimento é necessário; e (6) inclusão da perspectiva da microcomunidade no debate mais amplo de transformação organizacional. (ICHIJO, 2008, p. 131132)

Outor afirma ainda que:

Os ativistas do conhecimento são grandes participantes em pelo menos quatro subprocessos de criação de conhecimento. No início do processo, eles frequentemente formam microcomunidades de conhecimento. Eles facilitam o caminho para a criação e a justificação dos conceitos, assim como para a construção de um protótipo. (...) Os ativistas do conhecimento são os divulgadores do conhecimento na empresa, espalhando a mensagem a todos." (ICHIJO, 2008, p. 131-132).

Desta forma, verifica-se que para gerenciar o conteúdo de um livro eletrônico é necessário um ativista do conhecimento para cada área específica, para a qual se utilizará essa ferramenta. Para que todos deem sugestões, e elas sejam filtradas e sintetizadas de forma que fiquem claras para todos, para que o conhecimento seja compartilhado de maneira eficaz.

Rosini e Palmisano (2008) esclarecem bem a contribuição que um documento com informação digital pode oferecer:

\begin{abstract}
Quando a informação é digitalizada e comunicada por meio de redes digitais, revela-se um novo mundo de possibilidades, em que quantidades enormes de informação podem ser comprimidas e transmitidas na velocidade da luz, pois a quantidade das informações pode ser muito melhor do que nas transmissões analógicas. Muitas formas diferentes de informação podem ser combinadas, criando, por exemplo, documentos multimídia e as informações podem ser armazenadas e recuperadas instantaneamente de qualquer parte do mundo, propiciando, consequentemente, acesso instantâneo a maior parte das informações registradas pela civilização humana. (ROSINI; PALMISANO, 2008, p. 107, grifo nosso).
\end{abstract}

Um aspecto importante em um ativista é a sua capacidade de saber interagir com as pessoas e a capacidade de atuar como um suporte de ligação entre o conhecimento e as idéias tácitas advindas de diversas vivências de cada indivíduo.

Há que se mencionar a metáfora do Iceberg do Conhecimento, pois, de acordo com Sabbag (2007, p. 56-57) o conhecimento é explorado como se fosse em camadas de um iceberg. No topo do iceberg estão as partes que fazem parte do conhecimento explícito como o saber fazer (teorias, normas, procedimentos, instruções, processos organizacionais) e na parte submersa e intangível encontra-se a parte que compete ao conhecimento tácito como o saber fazer incorporado, saber os porquês, saber com quem (talentos naturais, simbolismos, crenças, cultura, valores e atitudes, pressupostos).

Neste contexto o ativista do conhecimento para atuar como ator no processo, deve saber lidar com as nuances existentes entre o conhecimento explícito e o que se pode aprender com o conhecimento tácito, uma vez que 
a profundidade com que terá que lidar com este último é maior e envolve um processo de extração do conhecimento individualizado.

Corroborando com essa ideia há a espiral do conhecimento (figura 1) proposta por Nonaka e Takeuchi (1997, p. 80), na qual observa-se que o grande desafio corresponde em transformar o conhecimento tácito em explícito, ou seja, no processo de externalização. E neste processo está a fundamental importância do papel do ativista: na compilação de toda essa gama de conhecimentos exteriorizados.

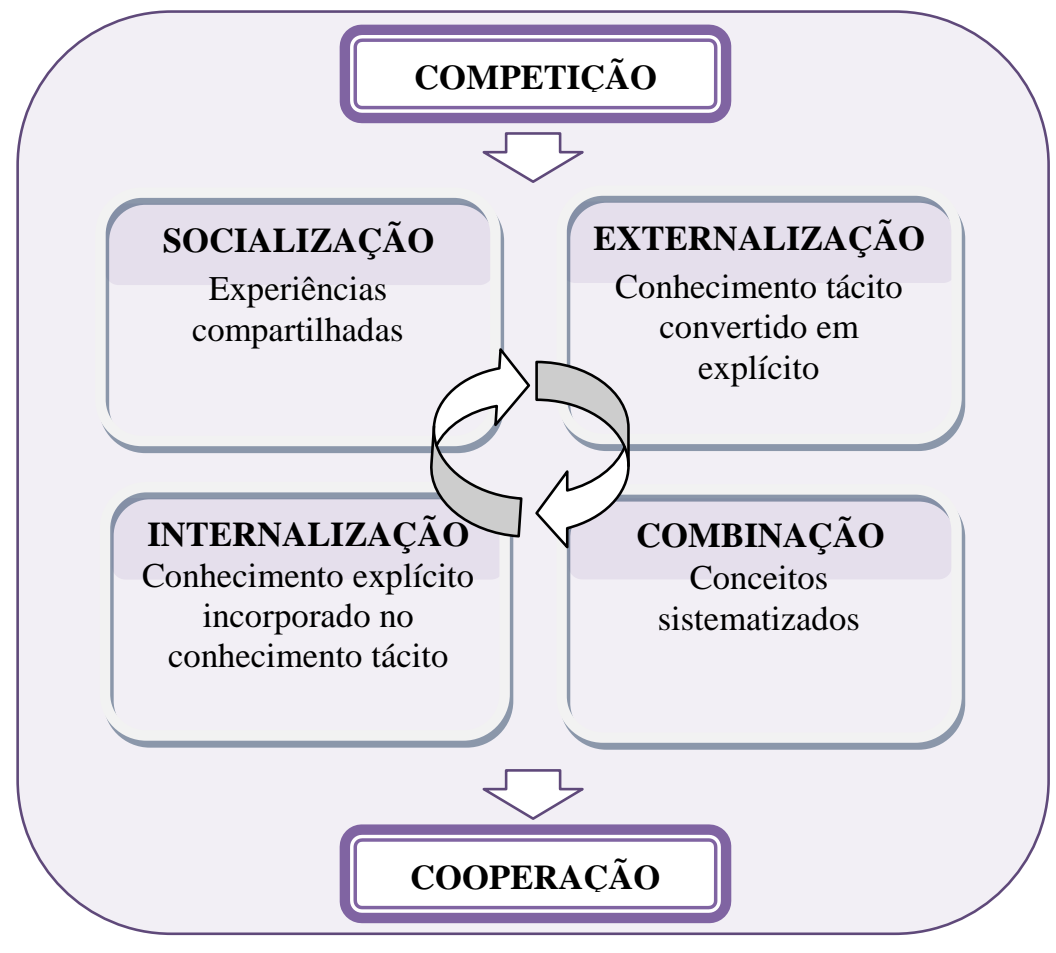

Figura 1: Espiral do Conhecimento

Fonte: adaptado de Nonaka e Takeuchi $(1997$, p. 80)

Neste cenário o ativista do conhecimento que está envolvido com a atividade de desenvolvimento de um livro eletrônico tem a função de ser um agente extrator do conhecimento tácito e um transformador deste conhecimento em explícito, por meio do método espiral do conhecimento de Nonaka e Takeuchi (1997), o ciclo de socialização, externalização, combinação e internalização, deve ser contínuo, possibilitando a troca de 
conhecimentos, o enriquecimento de saberes e a formalização do conhecimento.

Dessa forma a disseminação formal do conhecimento tende a ser um produto dos esforços da extração e transformação do conhecimento tácito em conhecimento explícito, tomando um formato materializado, ou seja, pode-se falar em uma concretização do conhecimento.

\section{MATERIALIZAÇÃO DO CONHECIMENTO}

Apesar do conhecimento ser algo muito comentado e discutido dentro das organizações, há ainda muita dificuldade nas empresas em realmente se utilizar adequadamente os conhecimentos gerados internamente. $\mathrm{Na}$ prática, gerir o conhecimento é algo de grande dificuldade para muitas instituições e uma das possíveis causas para isso, é a negligência das instituições no momento da externalização dos conhecimentos. Quem afirma isto são os autores Takeuchi e Nonaka (2008), pois, para eles, este processo tem sido amplamente negligenciado na literatura organizacional.

O conhecimento externalizado deve ser materializado, para ser disseminado corretamente, pois quando se trata de conhecimento é preciso se ter uma compreensão exata do que se pretende compartilhar dentro dos processos envolvidos, é importante saber mapear formalmente o conhecimento presente dentro das organizações.

Esse processo de materialização se dá pela necessidade de gerar uma estrutura concreta do conhecimento, nesse sentido, bem explicitada por Muñoz-Seca e Riverola:

\footnotetext{
Dada a intangibilidade do conhecimento para poder manejá-lo fisicamente, requer-se sua transformação em estruturas materiais. O conhecimento deve se incorporar a uma estrutura física que pode se transformar por meios físicos bem estabelecidos e da qual se pode extrair de novo por meios sensoriais. O conhecimento em forma pura não é suficiente para satisfazer todas as necessidades da economia. $O$ alimento para a mente deve ser suplementado com o alimento para o corpo. Por conseguinte, o conhecimento tem de ser transformado - também utilizaremos o termo "materializado" em entidades tratáveis dentro dos processos básicos da empresa e da sociedade. (MUÑOZ-SECA; RIVEROLA, 2004, p. 45).
}

Na mesma perspectiva, os autores continuam e explicam o que seria a materialização do conhecimento: 
As informações podem advir das reuniões informais, colaborativas e propiciar a todos informações precisas e atualizadas. O compartilhamento do conhecimento pode ocorrer por meio de práticas informais ou formais. As práticas diferem de uma organização para outra.

O compartilhamento informal, conforme Grotto (2003, p. 110) "geralmente, ocorre de maneira não preestabelecida durante encontros casuais e conversas locais, quando as pessoas trocam ideias, pedem conselhos para resolver problemas e perguntam em que os outros estão trabalhando".

À luz do compartilhamento formal do conhecimento e de acordo com alguns conceitos tem-se a possibilidade de se obter um cenário, no qual, segundo o autor "existem algumas práticas formais de compartilhamento do conhecimento - como palestras, apresentações audiovisuais, manuais e livros - propícias ao compartilhamento do conhecimento explícito" e algumas ferramentas tecnológicas para esse compartilhamento formal do conhecimento, como "o e-mail, a videoconferência e o sistema de redes (...) e o mapeamento do conhecimento organizacional" (GROTTO, 2003, p. 111-112); o autor ainda cita duas práticas de compartilhamento de conhecimento encontradas em empresas distintas: a) estratégia de codificação, na qual o conhecimento é explicitado em sistemas de informação para acesso pelos colaboradores; e b) estratégia personalizada, na qual uma pessoa detentora do conhecimento é responsável por comunicá-lo e transmiti-lo aos demais interessados. Essas duas práticas, unidas podem propiciar grande desenvolvimento de conhecimento dentro da organização.

Verifica-se, com essa explanação a importância da tecnologia no compartilhamento formal do conhecimento dentro das organizações, no entanto percebe-se um implicador: a fragmentação desses recursos.

Se as empresas considerarem exatamente o que o autor comenta uso de e-mail, vídeoconferência e o sistema de redes - terá conhecimento materializado, passível de ser disseminado a quem interessar, porém fragmentado.

Há então a necessidade de uma ferramenta para a disseminação formal do conhecimento de forma a unir todas essas informações em um único local, de acesso fácil, remoto, portátil e seguro. Trata-se da portabilidade e da disponibilidade desses conhecimentos em tempo hábil, quando necessário.

O livro eletrônico vem como aliado a essa disponibilidade de conhecimentos nas organizações, como estratégia de armazenamento e disseminação de novos conhecimentos, de forma externalizada formal e unificada.

\section{O LIVRO ELETRÔNICO COMO ESTRATÉGIA PARA A GESTÃO DO CONHECIMENTO}

O livro impresso é estático e corre o risco de ficar defasado muito rapidamente. O livro eletrônico tem a possibilidade de oferecer mais, 
oferecer principalmente a atualização de informações, de conteúdo, de conhecimentos.

Teixeira Filho (2000) comenta a necessidade das empresas em relação ao compartilhamento do conhecimento:

O conhecimento é transmitido por pessoas e para pessoas, através de meios estruturados como vídeos, livros, documentos, páginas da Web, etc. Além disso, as pessoas obtêm conhecimento daqueles que já o têm, pelo aprendizado interpessoal e o compartilhamento de experiências e ideias. (...) As empresas precisam de qualidade, valor agregado, serviço, inovação, flexibilidade, agilidade e velocidade de forma cada vez mais crítica (TEIXEIRA FILHO, 2000p. 22-23).

O livro eletrônico pode unir tudo o que foi mencionado por Teixeira Filho, pode auxiliar nos processos (disseminando, armazenando e atualizando conhecimentos) como pode agregar todos os "produtos" em si próprio (documentos, textos, hipertextos, vídeos, livros, publicações, emails, sites), tudo de uma forma agradável, amigável e de acesso fácil e ágil.

Se a empresa seguir as ideias de Nonaka e Takeuchi (1997), sobre a socialização, externalização, internalização e a combinação poderá registrar tudo isso em livros eletrônicos, que podem ser acessados na empresa, ou mesmo em casa, ou em viagens, pelos seus colaboradores.

Conforme Santiago Júnior (2004) é possível verificar que

\begin{abstract}
A maioria dos problemas sobre a disponibilidade de conhecimentos nas organizações recai nas seguintes questões: a) problemas com transferência do conhecimento; b) erros devidos à falta de conhecimento; $\mathrm{c}$ ) conhecimento crítico nas mãos de poucas pessoas; d) impossibilidade de medição de uso do conhecimento; e) perda de conhecimentos relevantes nos momentos adequados; f) falta de processos de compartilhamento. (SANTIAGO JÚNIOR, 2004, p. 25).
\end{abstract}

O uso de livros digitais supriria praticamente todas as questões citadas pelo autor. De acordo com Rezende (2002) existem os Sistemas do Conhecimento, no qual o livro eletrônico se enquadra como uma estratégia para a Gestão do Conhecimento. Conforme o autor, nos sistemas do conhecimento são gerados muitas informações com conhecimento agregado. Para o autor:

Todo e qualquer sistema que manipula ou gera conhecimentos organizados para contribuir com os seres humanos, com as organizações e com a sociedade como um todo, pode ser chamado de Sistema do Conhecimento. Isso significa a difusão das informações relevantes e úteis, "trabalhadas" por pessoas e/ou recursos computacionais, produzidas com qualidade e de forma antecipada, transformando-as em conhecimento explícito, que possa ser utilizado por todas as pessoas da organização, como suporte à obtenção da vantagem competitiva inteligente. (REZENDE, 2002, p. 85)

O livro eletrônico como toda tecnologia tem seus pontos positivos e pontos negativos, ainda assim seus pontos negativos em sua maior parte 
são superados com adequações que podem ser promovidas pelo ativista do conhecimento e pela colaboração de seus usuários. Destacam-se:

- $\quad$ Pontos positivos dos livros eletrônicos: portabilidade; reunião de conteúdos textuais e multimídia; atualização de conteúdo; convergência de tecnologia; disponibilidade e agilidade; controle de acesso ao conteúdo pelo usuário e pelo moderador.

- Pontos negativos dos livros eletrônicos: necessidade de um aparelho eletrônico para sua leitura; prática do uso de proteção de direitos autorais (improvável num modelo como esse proposto); falta de cultura em leitura eletrônica; falta de pro-atividade e interesse do usuário quanto ao conteúdo.

A figura 2 ilustra a união entre o compartilhamento "informal", por meio dos colaboradores, sua disponibilização ao ativista do conhecimento e o compartilhamento formal, que seria a materialização deste conhecimento pelo ativista, transformando-o em conteúdo de um suposto livro eletrônico que é disponibilizado novamente para todos os colaboradores.

Desta forma, esse livro eletrônico seria sempre alimentado pelo ativista do conhecimento a cada novo conteúdo (conhecimento) compartilhado, externalizado e materializado. A unificação de todos os conhecimentos estaria garantida e reunida em um local único de fácil acesso e portabilidade. Seu acesso pode ser feito em qualquer lugar, já que o seu aparelho leitor pode ser desde um computador a um aparelho de celular, garantindo a mobilidade e acessibilidade do conhecimento que se busca. 


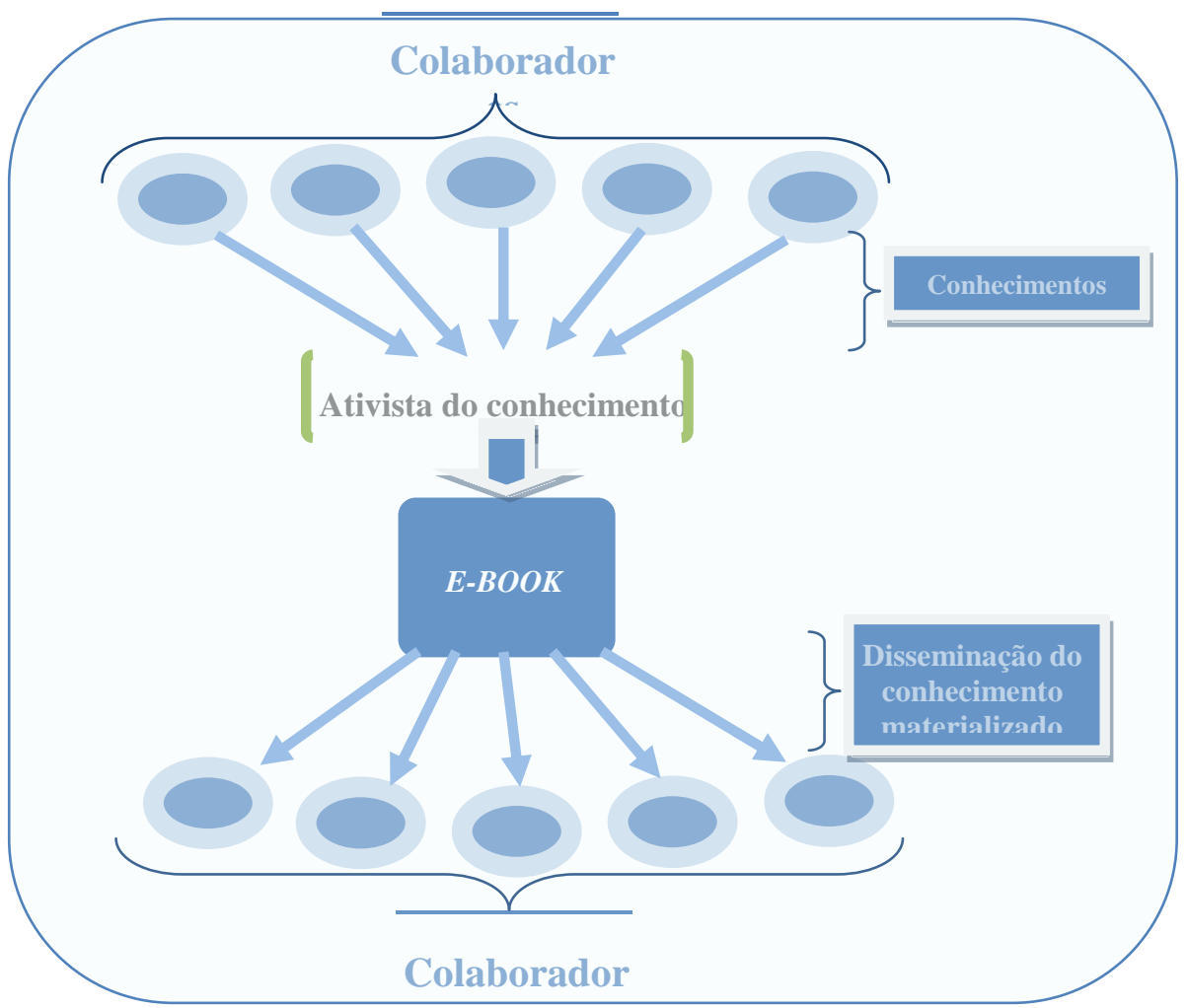

Figura 2: Processo de materialização e disseminação de conhecimento por meio de e-books

Fonte: Elaborado pelos autores.

\section{CONSIDERAÇÕES FINAIS}

O principal objetivo desse artigo foi mostrar uma proposta do uso do livro eletrônico (e-book) como uma ferramenta para a disseminação do conhecimento materializado, levando em consideração os conceitos e métodos sobre a Gestão do Conhecimento, bem como a forma como este conhecimento é articulado dentro das organizações. Trata-se de um meio de compartilhamento formal do conhecimento explícito materializado, por meio de trabalhos como o do ativista do conhecimento, que deve ser o responsável pela concretização das ações necessárias à disponibilização de ambiente propício e ferramentas necessárias à captação desse conhecimento, para então transpô-los ao e-book, de forma que este seja fornecido aos colaboradores como ferramenta estratégica para a disseminação formal do conhecimento.

É muito importante o papel do ativista do conhecimento, também observado por Simcsik e Polloni (2002) e Ichijo (2008), no processo de coleta dos conhecimentos tácitos e a compilação e transformação destes conhecimentos externalizados em conhecimento explícito. Materializar 
esses conhecimentos para disponibilizá-los em e-books torna-se um desafio e um ponto crucial para que a proposta em tela seja concretizada, de forma a atingir as necessidade de compartilhamento de conhecimentos em qualquer organização. Como afirmado por Fleury e Oliveira Junior (2010, p. 18) os conhecimentos tácitos de um grupo de pessoas em uma organização são as competências essenciais da empresa. Sendo possível observar que para disseminar os conhecimentos a tarefa de materializa-los é necessária.

Desta forma concorda-se com Spender, quando afirma que "há valor óbvio em inventariar esse conhecimento e em usar o poder da moderna tecnologia para torná-lo prontamente disponível a qualquer que seja a necessidade" (SPENDER, 2010, p. 30-31).

$O$ resultado obtido com os artigos analisados e com o levantamento bibliográfico mostra que para as organizações o conhecimento é aspecto fundamental para a competitividade e para a própria sobrevivência, auxiliando na tomada de decisões pelo compartilhamento dos conhecimentos. No entanto, têm negligenciado a etapa de externalização do conhecimento, conforme afirmado por Takeuchi e Nonaka (2008).

Neste aspecto a disponibilidade, o compartilhamento, o acesso, a disseminação e a sistematização se fazem necessários para que a complexidade dos processos organizacionais se unifiquem para atingir os objetivos estipulados no planejamento estratégico.

Surge neste contexto a preocupação com a espiral do conhecimento, conforme apresentado e defendido por Nonaka e Takeuchi (1997), para tornar o conhecimento tácito em explícito por meio da externalização e indo além se faz necessária a sistematização desse conhecimento.

Essa sistematização e seu compartilhamento ocorre formal ou informalmente, como afirma Grotto (2003), desta forma o estudo mostra que a organização deve se preocupar com a formalização do compartilhamento dos conhecimentos, para que eles possam atingir a todos os objetivos desejados pela organização satisfazendo as necessidades de conhecimentos de seus colaboradores.

Por fim, o processo de materialização, concordando com Muñoz-Seca e Riverola (2004) e a disseminação do conhecimento por meio de e-books pode apresentar-se como uma ferramenta útil dentro das organizações possibilitando resultados positivos e satisfatórios, conforme afirmado por Rosini e Palmisano (2008), uma vez que o conhecimento pode ser acessado pelo usuário utilizando-se de diversas tecnologias desde um computador até um aparelho celular, isto em tempo real, o que garante a temporalidade, acessibilidade, integridade do conhecimento que se deseja naquele espaço de tempo. Desta forma suprem-se as necessidades afirmadas por Santiago Júnior (2004), concordando com Rezende (2002) em relação aos Sistemas de Conhecimento. 


\section{REFERÊNCIAS}

BARRETO, A. D. A. A condição da informação. In: STAREC, C.; GOMES, E.; BEZERRA, J. Gestão estratégica da informação e inteligência competitiva. São paulo: Saraiva, 2006.

BARRETO, J. O bisavô do iPad. Info Abril, São Paulo, n. 302, abr. 2011.

BENíCIO, C. D. Do livro impresso ao e-book. 2003. 142 f. Trabalho de conclusão de curso (Graduação em Biblioteconomia) - Faculdade de Biblioteconomia, Universidade Federal da Paraíba, João Pessoa, 2003.

BENÍCIO, C. D.; SILVA, A. K. A. D. Do livro impresso ao ebook: o paradigma do suporte na biblioteca eletrônica. Biblionline, v. 1, n. 2, 2005.

BUFREM, L. S.; SORRIBAS, T. V. Práticas de leitura em meio eletrônico. ETD - Educação Temática Digital, Campinas, n. 1, v. 11, p. 298-326, dez. $2009 . \quad$ Disponível em: <http://www.fe.unicamp.br/revista/index.php/etd/article/view/2038/pdf_112>. Acesso em: 12 jul. 2011.

CHOO, C. W. A organização do conhecimento: como as organizações usam a informação para criar significado, construir conhecimento e tomar decisões. 2. ed. São Paulo: SENAC, 2006.

DUGUID, P.; BROWN, J. S. Estrutura e espontaneidade: conhecimento e organização. In: FLEURY, M. T. L.; OLIVEIRA JUNIOR, M. D. M. O. Gestão estratégica do conhecimento: Integrando aprendizagem, conhecimento e competências. São Paulo: Atlas, 2010.

DZIEKANIAK, G. V. Considerações sobre o e-book: do hipertexto à preservação digital. Biblos: Revista do Instituto de Ciências Humanas e da Informação, n. 2, v. 1, p. 83-99, 2010. Disponível em: $<$ http://www.brapci.ufpr.br/download.php?dd0 $=16400>$. Acesso em: 15 ago. 2011.

FLEURY, M. T. L.; OLIVEIRA JUNIOR, M. D. M. O. Gestão estratégica do conhecimento: Integrando aprendizagem, conhecimento e competências. São Paulo: Atlas, 2010.

GARCIA, B. Futuros possíveis para o mercado editorial. Webinsider, 14 set. 2010. Disponível em: <http://webinsider.uol.com.br/2010/09/14/futurospossiveis-para-o-mercado-editorial>. Acesso em: 15 jul. 2010.

GUTENBERG. Projeto Gutenberg. 2008. Disponível em: <http://www.gutenberg.org/wiki/Gutenberg:About>. Acesso em:

ICHIJO, K. Da administração à promoção do conhecimento. In: TAKEUCHI, H.; NONAKA, I. Gestão do conhecimento. Porto Alegre: Bookman, 2008. 
IDPF. EPUB 3 Working Group Charter. International Digital Publishing Forum, 24 maio 2010. Disponível em: <http://idpf.org/epub/30/wg-charter>. Acesso em: ago. 2011.

MUÑOZ-SECA, B.; RIVEROLA, J. Transformando conhecimento em resultados: a gestão do conhecimento como diferencial na busca de mais produtividade e competitividade. São Paulo: Clio, 2004.

NONAKA, I.; TAKEUCHI, H. Criação de conhecimento na empresa. Rio de Janeiro: Campus, 1997.

REZENDE, D. A. Tecnologia da informação integrada à inteligência empresarial: alinhamento estratégico e análise da prática nas organizações. São Paulo: Atlas, 2002.

RODRIGUES, S. B. De fábricas a lojas de conhecimento: as universidades e a desconstrução do conhecimento sem cliente. In: FLEURY, M. T. L.; OLIVEIRA JUNIOR, M. D. M. O. Gestão estratégica do conhecimento: Integrando aprendizagem, conhecimento e competências. São Paulo: Atlas, 2010.

ROSINI, A. M.; PALMISANO, A. Administração de sistemas de informação e a gestão do conhecimento. São Paulo: Cengage Learning, 2008.

SABBAG, P. Y. Espirais do conhecimento: ativando indivíduos, grupos e organizações. São Paulo: Saraiva, 2007.

SANTIAGO JÚNIOR, J. R. S. Gestão do conhecimento: a chave para o sucesso empresarial. São Paulo: Novatec, 2004.

SILVA, G. M. S.; BUFREM, L. S. Livro eletrônico: a evolução de uma ideia. In: INTERCOM, editor. Congresso Brasileiro da Comunicação. Campo Grande; 2001.

SIMCSIK, T.; POLLONI, E. G. F. Tecnologia da informação automatizada.

São Paulo: Berkeley, 2002.

TAKEUCHI, H.; NONAKA, I. Criação e dialética do conhecimento. In:

Gestão do Conhecimento. Porto Alegre: Bookman, 2008.

TEIXEIRA FILHO, J. Gerenciando conhecimento: como a empresa pode usar a memória organizacional e a inteligência competitiva no desenvolvimento de negócios. Rio de Janeiro: Senac, 2000.

TORQUATO, C. Prefácio: a Sociedade da informação na era digital. In: POLIZELLI, D. 
YANO, C. Compare 14 modelos de leitores de livros digitais.

Exame.com, Tecnologia, São Paulo, 23 jul. 2010. Disponível em: <http://exame.abril.com.br/tecnologia/noticias/compare-14-modelos-deleitores-de-livros-digitais? $p=1$ >. Acesso em: 10 ago. 2011. 